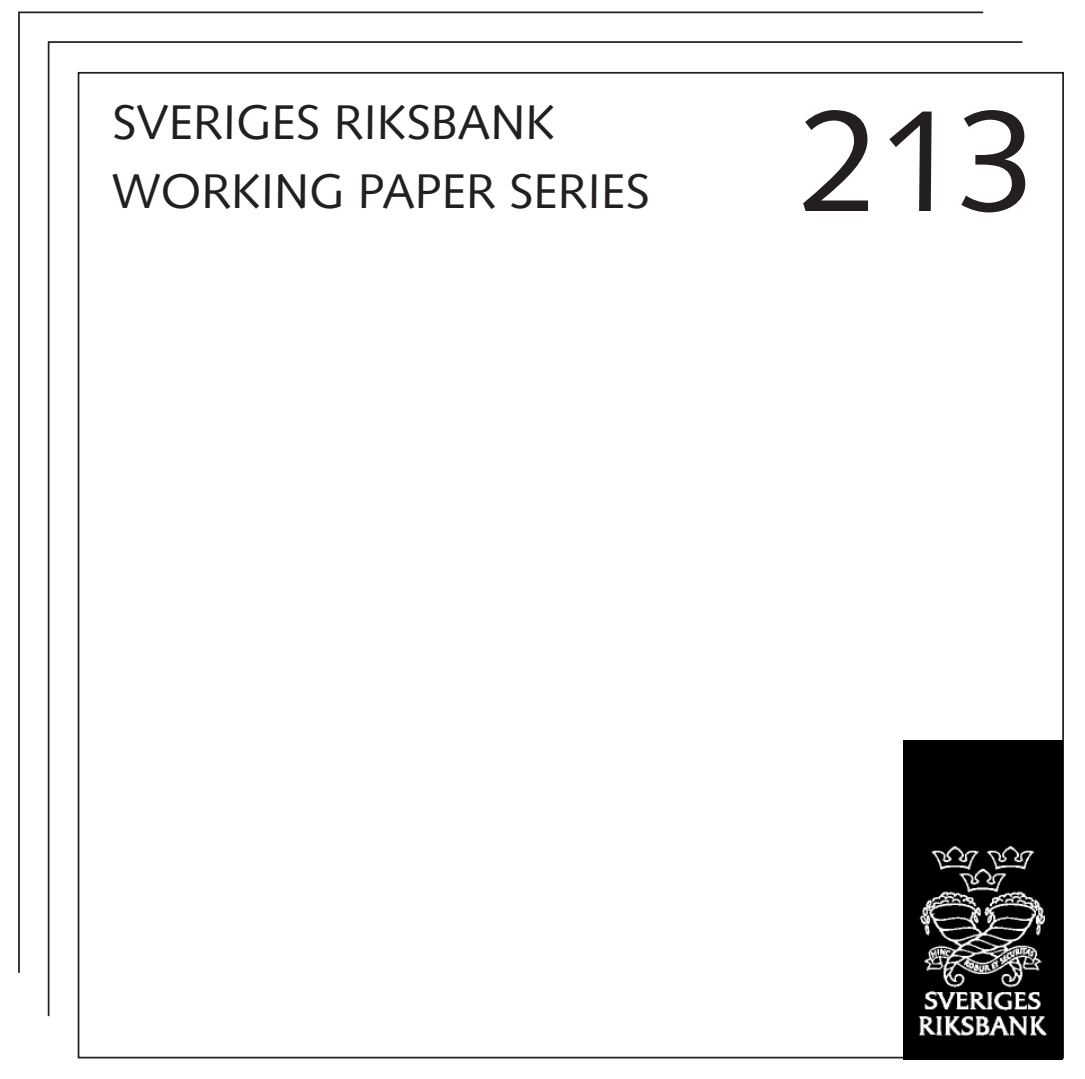

Using a New Open Economy Macroeconomics model to make real nominal exchange rate forecasts

Peter Sellin

OCTOBER 2007 
WORKING PAPERS ARE OBTAINABLE FROM

Sveriges Riksbank •Information Riksbank • SE-103 37 Stockholm Fax international: +4687870526

Telephone international: +4687870100

E-mail: info@riksbank.se

The Working Paper series presents reports on matters in the sphere of activities of the Riksbank that are considered to be of interest to a wider public.

The papers are to be regarded as reports on ongoing studies and the authors will be pleased to receive comments.

The views expressed in Working Papers are solely the responsibility of the authors and should not to be interpreted as reflecting the views of the Executive Board of Sveriges Riksbank. 


\title{
Using a New Open Economy Macroeconomics \\ model to make real and nominal exchange rate
}

\author{
forecasts*
}

\author{
Peter Sellin* \\ Sveriges Riksbank Working Paper Series
}

No. 213

October 2007

\begin{abstract}
In this paper we undertake an out-of-sample evaluation of the ability of a model to forecast the Swedish Krona's real and nominal effective exchange rate, using a cointegrating relation between the real exchange rate, relative output, terms of trade and net foreign assets (or alternatively the trade balance). The cointegrating relation is derived from a theoretical model of the New Open Economy Macroeconomics type. The forecasting performance of our estimated vector error correction model is quite good once the dynamics of the model have been augmented with an interest rate differential.
\end{abstract}

Keywords: New Open Economy Macroeconomics; real exchange rate; nominal exchange rate; forecasting

JEL classification: C52; C53; F31

\footnotetext{
${ }^{*}$ I am grateful for helpful comments by Hans Dillén, Paolo Giordani, Jesper Hansson, Tor Jacobson, Jesper Lindé, Anders Vredin, Mattias Villani and participants at a seminar at Sveriges Riksbank. The views expressed in this paper should not be interpreted as reflecting the views of the Executive Board of Sveriges Riksbank.

* Monetary Policy Department, Sveriges Riksbank, SE-103 37 Stockholm, e-mail: peter.sellin@riksabnk.se.
} 


\section{Introduction}

A standard New Open Economy Macroeconomics (NOEM) model typically finds that the steady-state real exchange rate is related to the relative productivity in the tradables sector, the terms of trade and the net foreign asset position (see for example Lane and Milesi-Ferretti (2004) and Obstfeld and Rogoff (2005)). In this paper we will test if forecasts from a vector error correction model based on the Lane and MilesiFerretti (2004) model can beat a random walk at horizons of 1 to 12 quarters. A simple extension of the empirical model allows us to consider forecasts of the nominal as well as the real effective exchange rate. We find that the model forecasts for the Swedish krona are quite satisfactory, especially for the real exchange rate, once the dynamics of the model have been properly specified. A favourable comparison with the forecasts of a VAR in first differences lends support to the theoretical model.

The out-of-sample forecasting performance of exchange rate models poses a special challenge to open economy macroeconomists. The standard finding in the empirical literature, starting with the seminal article by Meese and Rogoff (1983) evaluating the models of the 1970 's, is that no model can consistently outperform a random walk. For an evaluation of the models of the 1990's see Cheung, Chinn and Pascual (2005). However, the tests used have not been appropriate for testing nested models, as has been pointed out by for example Clark and McCracken (2001). Now research in this area has started using inference procedures that have recently been developed by Clark and West (2006a, 2006b). Their test procedure corrects for an upward bias in the alternative model's sample mean squared prediction error. The test is easy to use and can also be applied to multi-step forecasts, using standard normal inference. Gourinchas and Rey (2005), Alquist and Chinn (2006) and Melodtsova and 
Papell (2006) use the new test. The results are somewhat more supportive regarding the ability of forecasts from exchange rate models to beat a random walk.

Gourinchas and Rey (2005) estimate a model of the effective US dollar exchange rate using the ratio of net exports to net foreign assets as explanatory variable. They present forecasts that are consistently better than a random walk at horizons of 1 to 16 quarters over the period 1978:1 to 2004:1. Alquist and Chinn (2006) consider three different models: the sticky price monetary model, the uncovered interest rate parity relation and Gourinchas and Rey's (2005) model. Alquist and Chinn investigate the dollars bilateral exchange rates relative to the Canadian dollar, the UK Pound, the Japanese yen and the euro. They could not identify a model that was able to outperform a random walk forecast for all horizons and all bilateral exchange rates considered. However, the Gourinchas and Rey model did quite well for short forecast horizons of 1 and 4 quarters, except for the JPY/USD exchange rate. Molodtsova and Papell (2006) consider several models: the flexible price monetary model, uncovered interest parity, purchasing power parity and two types of Taylor rule models. They also consider a greater number of US bilateral exchange rates compared to Alquist and Chinn. They find that the models perform quite well at short forecast horizons. This is especially true for the Taylor rule models.

The Swedish real effective exchange rate has been modelled recently by Alexius and Nilsson (2000), Bergvall (2002), Lindblad and Sellin (2003), Nilsson (2004), and Lane (2006). Except for the first study, a common finding is that an improvement in the terms of trade lead to an appreciation of the real exchange rate. The first four studies also find that an increase in relative productivity (or relative output) leads to an appreciation, while Lane (2006) finds such a variable to be insignificant and excludes it from the analysis. However, none of the papers mentioned above subjected 
the underlying model to the severe test of out-of-sample forecasting ability, which is the main evaluation criteria in this paper. Also, our long-run exchange rate equation is derived from a calibrated NOEM model and we test the usefulness of the underlying theoretical model for forecasting purposes. ${ }^{1}$

The outline of the paper is the following. In Section 2 we present the steady-state exchange rate equation derived by Lane and Milesi-Ferretti (2004). In Section 3 we estimate a vector autoregressive model and analyse a possible cointegrating relation among the variables that is consistent with the theoretical model. The model is then extended to a model for the nominal exchange rate. In Section 4 we evaluate forecasts of the real and nominal effective exchange rate, using the inference procedures developed by Clark and West (2006a, 2006b). Section 5 concludes.

\section{A model of the real exchange rate}

We will base our analysis on the theoretical model derived in Lane and Milesi-Ferretti (2004). The main result in their paper is that higher steady state tradable output endowment $\left(Y_{T}\right)$, terms of trade $\left(P_{T}^{x}\right)$, and net foreign assets $(B)$ lead to a higher relative price of nontradables. The latter follows since an increase in any of the factors mentioned leads to greater wealth and hence increased demand for goods and leisure, the latter inducing a reduction in the supply of labour used (exclusively) in the production of nontradables.

The derived steady-state variation in the real exchange rate is $(\log )$ linear in the price of nontradables:

$$
-q=(1-\gamma) \log \left(P_{N}\right)
$$

\footnotetext{
${ }^{1}$ We do this by comparing the forecasts of our estimated vector error correction model to those of a vector autoregressive model in first differences.
} 


$$
=(1-\gamma) \Omega+(1-\gamma) \lambda \log \left(Y_{T}\right)+(1-\gamma) \lambda \log \left(P_{T}^{x}\right)+\frac{(1-\gamma) \lambda r}{\gamma} \frac{B}{Y_{0}}
$$

where $q$ is the log of the real exchange rate defined as the foreign price level relative to the domestic price level, $(1-\gamma)$ is the weight placed on consumption of nontraded goods in the utility function, $\Omega$ is a constant, $\lambda=(1+\sigma)[(1-\gamma) \theta+(\gamma+\theta) \sigma]^{-1}$ with $\sigma$ the intertemporal elasticity of substitution and $\theta$ the elasticity of substitution between traded and nontraded goods, $r$ is the exogenously given real interest rate, $Y_{0}$ is the steady-state output. Thus, higher net foreign assets and tradable output as well as an improvement in the terms of trade lead to an appreciation of the real exchange rate.

Equation (1) rewritten in obvious notation as

$$
0=q+\delta+\beta_{1} \log \left(Y_{T}\right)+\beta_{2} \log \left(P_{T}^{x}\right)+\beta_{3} \frac{B}{Y_{0}}
$$

forms the basis for our empirical analysis. To get some rough idea of the size of the coefficients we should expect to see we shall make some assumptions about the size of the elasticities above. We will assume an elasticity of substitution between traded and nontraded goods of $\theta=0.74$, as estimated by Mendoza (1995) for a sample of industrialised countries. Adolfsson et al (2005) set the share of imports in aggregate consumption to 0.31 for the Euro area. In addition to imports, traded goods should also include exportable goods. In view of this it does not seem unreasonable to choose the weight placed on consumption of traded goods in the utility function to $\gamma=0.5$. The elasticity of intertemporal substitution is set to $\sigma=0.67$ as in Mendoza (1995). With the final assumption that the real interest rate $r=0.01$ per quarter we get the parameter values $\left(\beta_{1}, \beta_{2}, \beta_{3}\right)=(0.7,0.7,0.014)$. 
Following Lane and Milesi-Ferretti (2002), we can use an alternative empirical formulation by noting that it is possible for a country to run a trade deficit in steadystate equal to the net investment income on its net foreign asset position:

$$
\frac{T B}{Y_{0}}=-r \frac{B}{Y_{0}}
$$

where $T B$ is the country's trade balance. Equation (2) can then be rewritten in the alternative form,

$$
0=q+\delta+\beta_{1} \log \left(Y_{T}\right)+\beta_{2} \log \left(P_{T}^{x}\right)+\beta_{3}^{*} \frac{T B}{Y_{0}}
$$

where we now expect $\left(\beta_{1}, \beta_{2}, \beta_{3}^{*}\right)=(0.7,0.7,-1.4)$.

We will estimate both specification (2) and (4) as a check on the robustness of the results and to see which model yields the better forecasts. We will also investigate whether the model with a theoretically restricted cointegration vector yields superior forecasts compared to the one with an estimated cointegration vector.

\section{Estimating a VAR model for the effective exchange rate}

\section{Preliminaries}

The benchmark model consists of four variables: real exchange rate, $q_{t}$, relative output, $y_{t}$, terms of trade, $\tau_{t}$, and net foreign assets relative to GDP, $b_{t}$. The first three variables are measured in natural logarithms. The real exchange rate is measured as the foreign price level relative to the Swedish price level expressed in the Swedish currency. Net foreign assets are measured as a fraction of gross domestic product. The alternative model also consists of four variables: real exchange rate, $q_{t}$, relative output, $y_{t}$, terms of trade, $\tau_{t}$, and the trade balance relative to GDP, $t b_{t}$. The 
quarterly value of the trade balance is expressed as a fraction of annual gross domestic product to conform to the measure of net foreign assets. More details about the data are given in an appendix.

The sample covers the period 1985Q1 - 2005Q3. The main reason for starting in 1985 is that we will consider an augmented version of the model that includes a shortterm interest rate differential and there was no secondary market for Treasury bills in Sweden before the early 1980s. Allowing for up to four lags would then take us back to the first quarter of 1984, by which time there was a working secondary market. By using $1985 \mathrm{Q} 1$ as the starting date we also avoid the devaluations of the early 1980 s and more than half of the observations are from the floating period 1993Q1-2005Q3.

Because of the small sample size some of the critical values of interest have been bootstrapped (using 4,999 replications in each case). The "Structural VAR Program" developed by Anders Warne has been used for this purpose. This program has also been used in order to investigate parameter stability. ${ }^{2}$ Otherwise, the results presented in most of the tables have been produced by the Eviews 5.0 program.

\section{The statistical model}

We will be using a 4-dimensional vector autoregressive (VAR) model of order $k$. This model can be expressed in vector error correction form (VEC) as:

$$
\Delta X_{t}=\alpha \beta^{\prime} X_{t-1}+\sum_{i=1}^{k-1} \Gamma_{i} \Delta X_{t-i}+\alpha \delta^{\prime}+\varepsilon_{t}
$$

where $X_{t}=\left(q_{t}, y_{t}, \tau_{t}, b_{t}\right)^{\prime}$ or alternatively $X_{t}=\left(q_{t}, y_{t}, \tau_{t}, t b_{t}\right)^{\prime}$. The errors are assumed to be independently and normally distributed with mean zero and covariance matrix $\Sigma$. Under certain conditions the $X_{t}$-process is non-stationary while both the first-

\footnotetext{
${ }^{2}$ See the Structural VAR homepage at http://texlips.hypermart.net/svar/index.html.
} 
differenced process $\Delta X_{t}$ and the linear combinations $\beta^{\prime} X_{t-1}$ are stationary (see Johansen (1996)). Based on the theoretical considerations discussed above we expect to find one such stationary linear combination, with $\beta \approx(1,0.7,0.7,0.014)$ or alternatively $(1,0.7,0.7,-1.4)$, when the vector is normalised with respect to the real exchange rate.

\section{The estimated benchmark model (BM)}

Our first order of business is to specify the correct number of lags for the VAR. In order to determine the lag order we considered a number of lag order selection criteria. The LR and AIC criteria indicated that a lag order of $k=3$ is optimal, the FPE criterion favoured 2 lags and the SC and HQ criteria preferred 1 lag. Lag exclusion tests indicated that we should keep 3 lags in the model. Multivariate tests of serially uncorrelated residuals for the $k=3$ model showed that the null hypothesis of no serial correlation in the residuals cannot be rejected at the 5 percent significance level against the alternative hypotheses of $1^{\text {st }}-4^{\text {th }}$ order serial correlation. Thus 3 lags were used. The null hypothesis that the residuals are normally distributed was rejected, using the test statistics derived by Doornik and Hansen (1994). The reason for this is that the kurtosis values are lower than those from a normal distribution. There was no indication of skewness in the residuals, which according to Juselius (2005) would be a more serious problem.

We performed tests for the cointegration rank $(r)$ for the $\operatorname{VAR}(3)$ model. We concluded from Johansen's likelihood ratio tests that there is one cointegrating vector, which is what we would expect from the theoretical model. Bootstrapping was then used for these test statistics. First, we found that bootstrapped critical values for the trace statistics were higher than the asymptotic values and we could not reject the null 
hypothesis of no cointegration. On the other hand a likelihood ratio test did not reject the hypothesis of $r=1$ against the alternative $r=0$ at conventional significance levels. Based on the above, we judged that the overall evidence against cointegration is not strong enough for us to give up our prior belief in one cointegration vector.

We computed the sample means and standard deviations of the first-differenced series. None of the means in the first-differenced series were significantly different from zero. We therefore restrict the constant term to the cointegration space to exclude deterministic drifts in the individual series. This implies that in the long run, or in the steady state, output in Sweden will grow at the same rate as in its main trading partners, export and import prices will grow at the same rate, and net foreign assets will converge to some constant fraction of GDP.

We have included two dummy variables in the estimated vector error correction model. The first is a devaluation dummy that takes the value one in the $4^{\text {th }}$ quarter of 1992 and zero otherwise and captures the real depreciation after letting the Krona float on 19 November 1992. This dummy variable is included contemporaneously and lagged one period. ${ }^{3}$ The second is a shift dummy and captures the change to an inflation targeting regime in the $1^{\text {st }}$ quarter of 1995 . It takes the value one up to and including the $4^{\text {th }}$ quarter of 1994 and zero thereafter.

Estimating the model by maximum likelihood is equivalent to solving an eigenvalue problem. We use the estimated non-zero eigenvalue to check for nonconstant parameters as suggested in Hansen and Johansen (1999). If the estimated eigenvalue fluctuates over time this can be due to fluctuations in $\beta$ or $\alpha$ or both and additional testing is required to determine which is the case. The time path of the

\footnotetext{
${ }^{3}$ Additional lags were tried, but were found not to be statistically significant.
} 
estimated non-zero eigenvalue looked quite stable, indicating no problem with nonconstant parameters in the cointegration relation.

The cointegration vector normalized with respect to the real SEK/TCW exchange rate is given by

$$
\hat{\beta}^{\prime}=[1.0, \underset{(-0.54,2.31)}{0.72}, \underset{(-0.02,1.05)}{0.50}, \underset{(-0.39,0.03)}{-0.17}]
$$

with 80 percent bootstrapped confidence intervals in parentheses below the estimated coefficients (using bootstrapped t-values). The coefficients are imprecisely estimated. However, we note that the point estimates of $\hat{\beta}_{1}$ and $\hat{\beta}_{2}$ are quite close to the values we expected them to take. On the other hand, $\hat{\beta}_{3}$ does not even take the expected sign. The estimated adjustment coefficients are

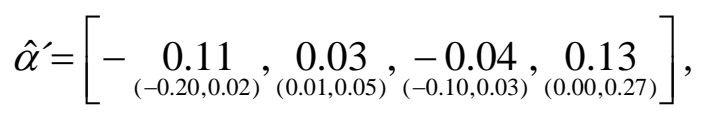

with 80 percent bootstrapped confidence intervals. An adjustment in the real exchange rate takes place with 11 percent of the gap being closed each quarter. We also note that the confidence interval includes the zero value. Thus, the adjustment is not significantly different from zero at the 20 percent level. The evidence of statistically significant adjustment in the second equation indicates that a weak exchange rate has a positive effect on relative output, which makes sense for an economy with a large export sector. ${ }^{4}$

We next restrict the model by imposing the theoretically derived cointegration vector of the previous section. The restriction is not rejected (the probability value is 0.34). The estimated adjustment coefficients for this model are

\footnotetext{
${ }^{4}$ See Lindé (2004) for a recent analysis of the extent to which the Swedish business cycle is driven by foreign shocks.
} 


$$
\hat{\alpha}^{\prime}=[-\underset{(-0.14,-0.00)}{0.09}, \underset{(0.01,0.04)}{0.02}, \underset{(-0.09,-0.00)}{-0.05}, \underset{(-0.02,0.14)}{0.05}] .
$$

For this specification the confidence interval for the adjustment in the real exchange rate does not include zero (by a small margin). The restrictions are deemed successful in the sense that imposing them gives us an adjustment coefficient estimate more supportive of the theoretical model.

Next we consider a model with richer dynamics. Since the theory does not have anything to say about the dynamics of the model we can freely choose to include variables that we feel could be important in the short run. A natural candidate is the short-term real interest rate differential. ${ }^{5}$ The inclusion of this variable could of course be motivated by an appeal to uncovered interest rate parity. On the other hand traders and analysts often claim to be trading on the opposite supposition, i.e. that a strategy of borrowing in a low interest rate currency and investing in a high interest rate currency will also gain from a favourable currency development. These are what is commonly referred to as "carry trades". A Granger causality test rejected the null hypothesis of no Granger causality from the interest rate differential to the exchange rate at the 6 percent significance level. We therefore add the real interest rate differential to the model and thus our new vector of endogenous variables is $X_{t}^{*}=\left(q_{t}, y_{t}, \tau_{t}, b_{t}, c i_{t}\right)^{\prime}$, where $c i_{t}$ is the cumulated real interest rate differential. The cumulated variable is restricted to zero in the cointegration vector so that we only end up with the interest rate differential, $i_{t}$, in the dynamics. The interest rate differential lagged one period enters with a negative sign and the coefficient is statistically

\footnotetext{
${ }^{5}$ The differential consists of the Swedish 3-month interest rate compared to a weighted 3-month rate consisting of interest rates for Sweden's main trading partners (using the TCW weights for Sweden). The real differential is simply obtained by adding the CPI inflation differential to the nominal interest rate differential.
} 
significant at the 10 percent level (using bootstrapped t-values); the two period lag is not significant. This result thus seems to give a rationale for the existence of carry trades. The estimated adjustment coefficients for this model are

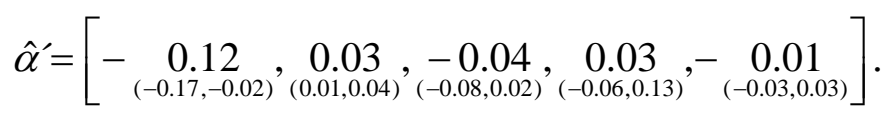

The cointegration relation for the restricted model is shown in Figure 3, Panel C. The adjustment in the real exchange rate is now clearly significant at the 80 percent confidence level.

\section{The estimated alternative model (AM)}

In the alternative model we have replaced the net foreign asset variable with the trade balance relative to GDP. Another difference is that we have excluded the inflation regime shift dummy from this model. ${ }^{6}$

All of the information criteria considered suggest that one lag should be adequate. But the lag exclusion test favours keeping 2 lags in the model. Estimating a VAR with one lag there is some evidence of serial correlation in the terms of trade residuals. With two lags this serial correlation goes away. Since it is not clear which model is to be preferred we choose to proceed with both $k=1$ and $k=2$.

Tests for the cointegration rank for the $\operatorname{VAR}(1)$ and $\operatorname{VAR}(2)$ models respectively give no reason to give up our prior belief in one cointegration vector. As in the benchmark model, bootstrapping the trace test critical values we cannot reject the null hypothesis of no cointegration. But a likelihood ratio test of $r=1$ against $r=0$ does not reject $r=1$ (with a probability value of 0.55 ). We will restrict the constant term to the

\footnotetext{
${ }^{6}$ Using the inflation regime shift variable in this model leads to very strange parameter estimates. The shift dummy is highly significant in the trade balance equation but the estimated coefficients in the cointegration vector become extremely large. We have therefore excluded the shift dummy from the model.
} 
cointegration space to exclude deterministic drifts in the individual series. This implies that in the long run the trade balance will converge to some constant fraction of GDP.

We check for non-constant parameters using the single non-zero eigenvalue, as explained in the previous section. The time path of the estimated non-zero eigenvalue looked reasonably stable.

The cointegration vector normalized with respect to the real exchange rate and the vector of adjustment coefficients are given by

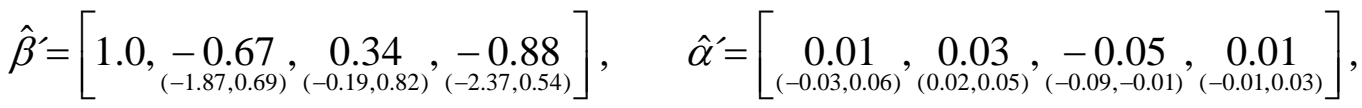

for the VEC with $k=1$ and for the VEC with $k=2$ we have

$\hat{\beta}^{\prime}=[1.0, \underset{(-1.66,0.63)}{-0.56} \underset{(0.01,0.85)}{0.45}, \underset{(-2.47,0.14)}{-1.18}], \quad \hat{\alpha}^{\prime}=\left[\begin{array}{c}-0.04 \\ (-0.10,0.03)\end{array} \underset{(0.02,0.05)}{0.04}, \underset{(-0.09,-0.01)}{-0.06}, \underset{(-0.01,0.04)}{0.02}\right]$,

with 80 percent bootstrapped confidence intervals in parentheses below the estimated coefficients (using bootstrapped t-values). The estimated coefficients of the VAR(2) model comes closest to what we expected to find. We note that the point estimates of $\hat{\beta}_{2}$ and $\hat{\beta}_{3}$ are quite close to the values we expected them to take. Disappointingly, $\hat{\beta}_{1}$ does not take the expected sign. However, the 80 percent confidence interval also contains positive values. The adjustment coefficient in the exchange rate equation is halved compared with the benchmark model and it is not statistically significantly different from zero at the 20 percent level.

We proceed by imposing the theoretically derived coefficient values in the cointegration vector of the $\mathrm{VEC}$ with $\mathrm{k}=2$. The restriction is not rejected at the 1 percent significance level (but is rejected at the 5 percent level). The estimated adjustment coefficients for this model are

$$
\hat{\alpha}^{\prime}=[-\underset{(-0.14,-0.01)}{0.08}, 0.03, \underset{(0.02,0.05)}{0}, \underset{(-0.10,-0.01)}{0.06}, \underset{(-0.02,0.03)}{0.01}] \text {. }
$$


The adjustment coefficient in the exchange rate equation is significantly different from zero at the 20 percent level and is equal in size to that estimated for the restricted benchmark model: -0.08 compared to -0.09 .

The estimated adjustment coefficients for the restricted model with an interest rate differential are

$$
\hat{\alpha}^{\prime}=[-\underset{(-0.19,-0.06)}{0.14}, \underset{(0.02,0.04)}{0.03}, \underset{(-0.07,0.02)}{-0.03}, \underset{(-0.011,0.05)}{0.02}, \underset{(-0.04,0.02)}{-0.01}] \text {, }
$$

with 80 percent bootstrapped confidence intervals. The interest rate differential lagged one period enters with a negative sign, which is significantly different from zero at the 5 percent level (using bootstrapped t-values). The results are very similar to those of the benchmark model. When the exchange rate is undervalued it tends to appreciate and growth is higher relative to growth in the rest of the world. The insignificance of the remaining three adjustment coefficients implies that the terms of trade, the trade balance, and the real interest rate differential are long-run exogenous. That an undervalued currency does not tend to improve the trade balance is a somewhat unexpected result.

\section{Estimating the nominal effective exchange rate}

When forecasting exchange rates the interest is usually in the nominal rather than in the real exchange rate. We will consider a very simple way of extending the analysis to get a forecasting model for the nominal exchange rate. This simply involves splitting up the real exchange rate into two components: the nominal exchange rate and the relative price level between the foreign and domestic country, $q_{t}=e_{t}+p_{t}$. We estimate the nominal versions of the restricted models augmented with an interest rate differential. Thus our new vector of endogenous variables is $X_{t}^{*}=\left(e_{t}, p_{t}, y_{t}, \tau_{t}, b_{t}, c i_{t}\right)^{\prime}$ 
for the benchmark model and $X_{t}^{*}=\left(e_{t}, p_{t}, y_{t}, \tau_{t}, t b_{t}, c i_{t}\right)^{\prime}$ for the alternative model. In this specification we use the nominal interest rate differentials. ${ }^{7}$

Estimating the nominal version of the benchmark model we obtain the following adjustment parameters:

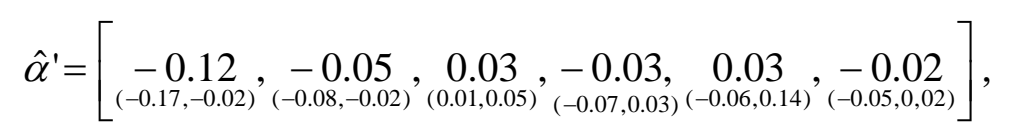

with 80 percent bootstrapped confidence intervals within parentheses below the estimated coefficients. We can see that the adjustment of the real exchange rate takes place both through the adjustment of the nominal exchange rate and through the adjustment of the relative price level. However, the point estimate for the adjustment coefficient in the nominal exchange rate equation is twice as big as the one in the relative price level equation. This is not surprising given that most of the sample covers the floating exchange rate period.

Estimating the nominal version of the alternative model we get the following adjustment parameters:

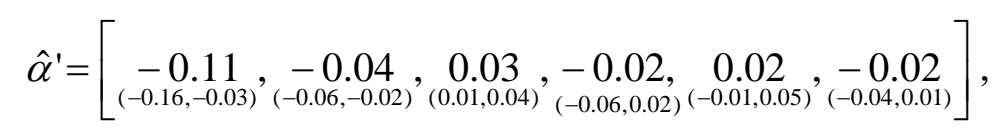

with 80 percent bootstrapped confidence intervals. These results are very similar to those of the benchmark model.

\section{Discussion}

Generally speaking, most of the estimated coefficients in the cointegration vector are imprecisely estimated and are not different from zero at the 20 percent significance level, using bootstrapped t-values. However, most of the point estimates are close to the values we would expect from the calibrated model. When we impose the

\footnotetext{
${ }^{7}$ Using the real interest rate differentials yielded very similar results.
} 
theoretically derived cointegration vectors they are not rejected by the data, i.e. we cannot reject cointegration. The estimated adjustment coefficients in the exchange rate equation and the relative output equation are significant with the expected signs. The real test of the models will be their out-of-sample forecast performance, to which we turn next.

\section{Forecast evaluation}

\section{The evaluation procedure}

We will evaluate forecasts of the percentage change in the exchange rate with horizons $h=1,2, \ldots, 12$ quarters. The first forecast will be based on the model estimated for the period 1985Q1 - 1997Q4. The estimation window is then moved forward by one quarter at a time using a rolling scheme. ${ }^{8}$ Thus, we are always using the latest 13 years of data to estimate the model parameters, including the cointegrating vector, which gives us 52 observations. The final 1-period forecast is for $2005 \mathrm{Q} 3$, which is the last observation in the sample. We thus get a total of $P-h+1 h$-period forecasts with $P=31$. Forecast accuracy is measured by mean squared prediction error (MSPE). With $a_{t+s+h}$ being the actual value and $f_{t+s+h}$ the forecast value, the MSPE for an $h$-period forecast is defined as:

$$
\hat{\sigma}^{2}(h)=\frac{1}{P-h+1} \sum_{s=0}^{P-h}\left(a_{t+s+h}-f_{t+s+h}\right)^{2},
$$

where $t=1997 \mathrm{Q} 4$. We will compare our forecasts with those of the random walk model, which says that the exchange rate will remain unchanged at the present level during

\footnotetext{
${ }^{8}$ We also conducted the analysis using a recursive scheme. The results were similar. We do not use a recursive scheme since the inference of our tests are not asymptotically valid for such a scheme, see Clark and West (2006a) and Giacomini and White (2006). West (2006) gives a useful overview of forecast evaluation techniques.
} 
the forecast period. We will also compare our forecasts to those of a VAR in first differences, i.e. leaving out the error correction term. This should tell us something about the value for forecasting purposes of using the theoretically derived cointegration relationship between the variables in levels.

Meese and Rogoff (1983) found that none of the exchange rate models developed during the 1970 s could consistently beat a random walk and this has been the benchmark for exchange rate forecasters ever since. In the spirit of Meese and Rogoff, Cheung, Chinn and Pascual (2005) evaluate the forecasting performance of the models developed during the 1990s, with equally disappointing results. However, as shown by Clark and McCracken (2001) among others, the tests employed in these studies are not appropriate when the models under comparison are nested. The tests are shown to be under-sized. Critical values are derived for the correct asymptotic distributions, but only for 1-step ahead forecasts.

Clark and West (2006a, 2006b) show that there is an upward bias in the nesting model's sample mean squared prediction error and how one can correct for this. The test is applicable also to multi-step forecasts and is easy to implement. We will use the bias correction suggested by Clark and West. Their MSPE-adjusted test statistic is defined as

$$
M S P E_{a d j}=\hat{\sigma}_{1}^{2}-\left(\hat{\sigma}_{2}^{2}-a d j .\right),
$$

where subscript 1 indicates the parsimonious (null) model and subscript 2 indicates the larger (alternative) model that nests model 1 (we have suppressed the horizon index $h$ ). The adjustment term is defined as

$$
\operatorname{adj} .(h)=\frac{1}{N-h+1} \sum_{s=0}^{N-h}\left(f_{1, t+s+h}-f_{2, t+s+h}\right)^{2} .
$$


This term adjusts for the upward bias in MSPE produced by the estimation of parameters that are zero under the null.

We implement the test by first defining

$$
\tilde{f}_{t+s+h}=\left(a_{t+s+h}-f_{1, t+s+h}\right)^{2}-\left\lfloor\left(a_{t+s+h}-f_{2, t+s+h}\right)^{2}-\left(f_{1, t+s+h}-f_{2, t+s+h}\right)^{2}\right\rfloor,
$$

The null hypothesis is equal MSPE. We test for equal MSPE by regressing $\tilde{f}_{t+s+h}$ on a constant and using the resulting $t$-statistic to test for a zero coefficient. Clark and West (2006a, 2006b) argue that standard normal critical values are approximately correct. We thus reject the null hypothesis of equal MSPE if this statistic is greater than +1.282 (for a one-tailed 0.10 test). ${ }^{9}$

Finally, we would like to draw attention to the fact that the seminal paper by Meese and Rogoff (1983) and many subsequent studies use the actual values for their exogenous regressors and still could not beat a random walk. Our exercise is more challenging in that the forecasts only involve endogenous variables. We make fully dynamic forecasts, i.e. a multi-period forecast uses predicted rather than actual values for all variables during the forecast period.

\section{Evaluating the forecasts}

In Table 1 we present the MSPEs for forecasts of the benchmark real exchange rate model (VEC), a random walk (RW), and a VAR in first differences, as well as the adjusted MSPEs. In the last two columns of the table we present the usual ratio of the (unadjusted) MSPEs and the t-values of the Clark-West statistic (for the adjusted MSPEs). We first compare the change in the exchange rate forecasted by the model to

\footnotetext{
${ }^{9} \mathrm{~A}$ one-tailed test is used since for nested models it does not make sense for the population MSPE of the parsimonious model to be smaller than that of the larger model. We use Newey-West autocorrelation consistent standard errors to construct the $t$-statistic because multi-period forecasts will in general be autocorrelated.
} 
a random walk forecast, which says that the exchange rate will remain unchanged. We see that the forecasts of the unrestricted model, i.e. with an estimated cointegrating vector (reported in Panel A), as well as those of the restricted model, i.e. with the theoretical cointegrating vector imposed (in Panel B), cannot beat a random walk. However, the forecasts of the restricted model augmented with an interest rate differential (reported in Panel C) are significantly better than those of a random walk at horizons of 5-10 quarters at the 10 percent significance level, using a one-tailed test. Thus, it is not enough to impose the theoretical cointegration vector. We also need to model the dynamics better by introducing some relevant variable like the real interest rate differential. Comparing the forecasts of the benchmark model to those from a simple VAR in first differences, in Panel C, we see that the restricted cointegration vector of the VEC model helps us to make better forecasts, which lends some support to the theoretical model.

In Table 2 we analyse the forecast performance of the alternative real exchange rate model. The results are similar to those reported for the benchmark model in that we need to augment the dynamics with an interest rate differential in order to beat a random walk forecast. The alternative model yields better forecasts in the short run but worse forecasts in the long run compared to the benchmark model (Panel C).

The forecasts from the nominal versions of the benchmark and alternative models are presented in Table 3, Panels A and B respectively. The predictive ability is not quite as good as for the real models, even though the forecasts of the alternative model are still fairly good. The AM forecasts outperform a random walk at practically all horizons. They do not outperform the forecasts from a simple VAR in first differences at conventional significance levels, but the t-values are close to one for forecast horizons of up to six quarters. 
The overall assessment is that we cannot reject the theoretical model as a description of how the real effective exchange rate is related to fundamental macroeconomic variables. But this conclusion is dependent on our ability to successfully model the dynamics about which the theoretical model has very little to say. We are successful in beating the random walk forecasts for both the real and nominal SEK/TCW exchange rates.

\section{Conclusions}

In this paper we test a model's ability to forecast the Swedish krona real and nominal effective exchange rates out of sample. We employ a new test procedure that is appropriate for the testing of nested models.

We use the steady-state relationship between the real exchange rate, relative output, terms of trade, and net foreign assets derived in Lane and Milesi-Ferretti (2004). We calibrate the model and derive coefficient values which are compared to the estimated coefficients in our vector error correction model. These are similar enough that we next impose the calibrated values on the cointegration vector. The restrictions are not rejected. When the dynamics of the empirical model have been augmented by including an interest rate differential the model yields forecasts that can beat a random walk at most horizons. We also conducted a test of the usefulness of the theoretically derived cointegrating vector by comparing the forecasts of the real exchange rate to those generated by a simple VAR in first differences. The model proved superior to the VAR at forecast horizons of 3-7 quarters. This means that the theoretical model helps us make better forecasts. We also had some success in making forecasts of the nominal exchange rate. 
Overall, using a New Open Economy Macroeconomic model to make real and nominal exchange rate forecasts proved quite successful. However, neglecting to properly model the dynamics of the model could result in inferior forecast performance. As a first step it seemed natural to include an interest rate differential to capture the short-run movements in the exchange rate. Other more elaborate ways of modelling the dynamics could be pursued in future research and could potentially yield even better forecasts. 


\section{Appendix: Data}

The data set spans the period 1984Q1 to 2005Q3. The data set thus allows for up to 4 lags in the models. Current data series are imported from EcoWin to the largest extent possible (series name within square brackets). Some of the series have been linked back in time to earlier series as indicated. Consumer price indexes are used to convert nominal exchange rates into real exchange rates. Terms of trade is computed as the ratio between export prices and import prices. Exchange rates and interest rates are computed as quarterly averages.

- SEK/TCW The nominal effective exchange rate using the IMF:s competitiveness weights (1991 vintage). The index is set equal to 100 on 18 November 1992, which can be translated into a value of 106.17 for the $4^{\text {th }}$ quarter of 1992. The real index has as its base November 1992=100. This translates into a value of 105.75 for the $4^{\text {th }}$ quarter of 1992. (Source: Sveriges Riksbank).

- Sweden, consumer price index [oecd:swe_cpaltt01_ixobq].

- TCW-weighted consumer price index (Source: Sveriges Riksbank).

- Sweden, export price index [ifs:s1447400dzfq].

- Sweden, import price index [ifs:s1447500dzfq].

- Sweden, gross domestic product, seasonally adjusted [ew:swe_01950]. This series is available starting 1993Q1. Data for 1984Q2-1992Q4 are from Sveriges Riksbank. An index is created which is set equal to 100 in 2000.

- TCW-weighted gross domestic product (Source: Sveriges Riksbank).

- Sweden, net international investment position, market valued FDI (Source: Sveriges Riksbank) This is an annual series. A quarterly series has been obtained by linearly interpolating so that the annual figure is reached in the $4^{\text {th }}$ quarter.

- Sweden, gross domestic product, current prices [oe:swe_gdpq]. This series has been seasonally adjusted using the X11 method.

- Exports [ifs:s14470000zfq]. Seasonally adjusted using X11 method.

- Imports [ifs:s14471000zfq]. Seasonally adjusted using X11 method.

- Sweden, interest rate on 3-month Treasury bill (Source: Sveriges Riksbank).

- TCW-weighted interest rate on 3-month Treasury bills (Source: Sveriges Riksbank). 


\section{References}

Adolfsson, M., S. Laséen, J. Lindé and M. Villani (2005). Bayesian estimation of an open economy DSGE model with incomplete pass-through, Working Paper No. 179, Sveriges Riksbank.

Alexius, A. and J. Nilsson (2000). Real exchange rates and fundamentals: evidence from 15 OECD countries, Open Economies Review 11, 383-397.

Alquist, R. and M.D. Chinn (2006). Conventional and unconventional approaches to exchange rate modelling and assessment, Working Paper No. 12481, National Bureau of Economic Research.

Bergvall, A. (2002). What determines real exchange rates? - The Nordic countries. Working Paper No. 2002:15, Uppsala University.

Cheung, Y-W, M.D. Chinn, and A.G. Pascual (2005). Empirical exchange rate models of the nineties: are any fit to survive? Journal of International Money and Finance 24, 1150-1175.

Clark, T.E. and M.W. McCracken (2001). Tests of equal forecast accuracy and encompassing for nested models. Journal of Econometrics 105, 85-110.

Clark, T.E. and K.D. West (2006a). Using out-of-sample mean squared prediction errors to test the martingale difference hypothesis. Journal of Econometrics 135(1-2), 155-186.

Clark, T.E. and K.D. West (2006b). Approximately normal tests for equal predictive accuracy in nested models. Journal of Econometrics, forthcoming.

Doornik, J.A. and H. Hansen (1994). A practical test for univariate and multivariate normality. Manuscript, Nuffield College, Oxford University, U.K.

Giacomini, R. and H. White (2006). Tests of conditional predictive ability, Econometrica 74(6), 1545-1578.

Gourinchas, P-O. and H. Rey (2005). International financial adjustment, Working Paper No. 11155, National Bureau of Economic Research.

Hansen, H. and S. Johansen (1999). Some tests for parameter constancy in cointegrated VAR-models, Econometrics Journal 2, 306-333.

Johansen, S. (1996). Likelihood-based inference in cointegrated vector autoregressive models, $2^{\text {nd }}$ ed. Advanced Texts in Econometrics. Oxford: Oxford University Press. 
Juselius, K. (2005). Lecture notes on advanced macroeconometrics.

Lane, P. (2006). The Swedish external position and the Kroner, mimeo, Trinity College, Dublin.

Lane, P. and G.M. Melesi-Ferretti (2002). External wealth, the trade balance, and the real exchange rate, European Economic Review 46, 1049-1071.

Lane, P. and G.M. Melesi-Ferretti (2004).The transfer problem revisited: Net foreign assets and real exchange rates, The Review of Economics and Statistics 86(4), 841857.

Lindblad, H. and P. Sellin (2003). The equilibrium rate of unemployment and the real exchange rate: an unobserved components system approach, Working Paper No. 152, Sveriges Riksbank.

Lindé, J. (2004). Swedish postwar business cycles: generated abroad or at home? Scandinavian Journal of Economics 106(4), 623-645.

Meese, R. and K. Rogoff (1983). Empirical exchange rate models of the seventies: do they fit out of sample? Journal of International Economics 53, 29-52.

Mendoza, E. (1995). The terms of trade, the real exchange rate, and economic fluctuations, International Economic Review 36(1), 101-137.

Molodtsova, T. and D. Papell (2006). The out-of-sample performance of empirical exchange rate models from the 1970's to the 2000's, mimeo, University of Houston, Houston, TX.

Nilsson, K. (2004). Do fundamentals explain the behaviour of the Swedish real effective exchange rate? Scandinavian Journal of Economics 106(4),603-622.

Obstfeld, M. and K. Rogoff (2005). The unsustainable US current account position revisited, revised version of Working Paper No. 10869, National Bureau of Economic Research.

West, K. (2006). Forecast evaluation. In Handbook of Economic Forecasting, Vol. 1, G. Elliot, C.W.J. Granger and A. Timmerman (eds.), Elsevier B.V. 
Table 1. Forecast evaluation: Real SEK/TCW benchmark model

Panel A. Unrestricted model

\begin{tabular}{cccccccc} 
Horizon & $\hat{\sigma}_{V E C}^{2}$ & $\hat{\sigma}_{V E C}^{2}$-adj. & $\hat{\sigma}_{R W}^{2}$ & $\hat{\sigma}_{V E C}^{2}$-adj. & $\hat{\sigma}_{V A R}^{2}$ & $\begin{array}{c}\hat{\sigma}_{V E C}^{2} / \hat{\sigma}_{R W}^{2} \\
(t \text {-value })\end{array}$ & $\begin{array}{c}\hat{\sigma}_{V E C}^{2} / \hat{\sigma}_{\text {VAR }}^{2} \\
(t \text {-value })\end{array}$ \\
\hline \hline 1 & 0.589 & 0.515 & 0.474 & 0.553 & 0.526 & $1.24(-0.67)$ & $1.12(-0.79)$ \\
2 & 1.403 & 1.317 & 1.067 & 1.333 & 1.296 & $1.31(-2.30)$ & $1.08(-0.37)$ \\
3 & 2.172 & 2.072 & 1.719 & 2.084 & 2.168 & $1.26(-2.41)$ & $1.00(0.38)$ \\
4 & 2.940 & 2.795 & 2.407 & 2.806 & 3.001 & $1.22(-2.03)$ & $0.98(0.53)$ \\
5 & 3.590 & 3.402 & 2.970 & 3.406 & 3.582 & $1.21(-1.89)$ & $1.00(0.38)$ \\
6 & 4.539 & 4.319 & 3.692 & 4.319 & 4.555 & $1.23(-2.35)$ & $1.00(0.40)$ \\
7 & 5.086 & 4.822 & 4.114 & 4.808 & 5.098 & $1.24(-2.37)$ & $1.00(0.43)$ \\
8 & 5.287 & 4.985 & 4.465 & 4.956 & 5.476 & $1.18(-1.34)$ & $0.97(0.64)$ \\
9 & 6.016 & 5.666 & 4.963 & 5.611 & 6.097 & $1.21(-1.38)$ & $0.99(0.53)$ \\
10 & 6.563 & 6.163 & 5.240 & 6.092 & 6.513 & $1.25(-1.42)$ & $1.01(0.41)$ \\
11 & 7.229 & 6.807 & 5.772 & 6.683 & 7.382 & $1.25(-1.28)$ & $0.98(0.50)$ \\
12 & 8.000 & 7.527 & 6.410 & 7.379 & 8.569 & $1.25(-1.10)$ & $0.93(0.65)$ \\
\hline \hline
\end{tabular}

\section{Panel B. Restricted model}

\begin{tabular}{cccccccc} 
Horizon & $\hat{\sigma}_{\text {VEC }}^{2}$ & $\hat{\sigma}_{\text {VEC }}^{2}$-adj. & $\hat{\sigma}_{R W}^{2}$ & $\hat{\sigma}_{\text {VEC }}^{2}$-adj. & $\hat{\sigma}_{\text {VAR }}^{2}$ & \begin{tabular}{c}
$\hat{\sigma}_{\text {VEC }}^{2}\left(\hat{\sigma}_{R W}^{2}(t\right.$-value $)$ \\
\hline \hline 1
\end{tabular}$\hat{\sigma}_{\text {VEC }}^{2} \hat{\sigma}_{\text {VAR }}^{2}(t$-value $)$ \\
\hline 2 & 0.544 & 0.431 & 0.474 & 0.493 & 0.526 & $1.15(0.43)$ & $1.03(0.35)$ \\
3 & 1.387 & 1.185 & 1.067 & 1.261 & 1.296 & $1.30(-0.44)$ & $1.07(0.11)$ \\
4 & 2.239 & 2.012 & 1.719 & 2.035 & 2.168 & $1.30(-0.85)$ & $1.03(0.28)$ \\
5 & 3.035 & 2.743 & 2.407 & 2.734 & 3.001 & $1.26(-0.81)$ & $1.01(0.39)$ \\
6 & 3.786 & 3.386 & 2.970 & 3.355 & 3.582 & $1.27(-0.85)$ & $1.06(0.28)$ \\
7 & 4.854 & 4.329 & 3.692 & 4.287 & 4.555 & $1.31(-1.06)$ & $1.07(0.28)$ \\
8 & 5.667 & 4.999 & 4.114 & 4.940 & 5.098 & $1.38(-1.21)$ & $1.11(0.15)$ \\
9 & 6.464 & 5.627 & 4.465 & 5.553 & 5.476 & $1.45(-1.28)$ & $1.18(-0.07)$ \\
10 & 7.499 & 6.478 & 4.963 & 6.384 & 6.097 & $1.51(-1.33)$ & $1.23(-0.22)$ \\
11 & 8.376 & 7.155 & 5.240 & 7.032 & 6.513 & $1.17(-1.31)$ & $1.29(-0.35)$ \\
12 & 9.782 & 8.320 & 5.772 & 8.195 & 7.382 & $1.69(-1.39)$ & $1.18(-0.49)$ \\
\hline \hline
\end{tabular}

Panel C. Restricted model with real interest rate differential

\begin{tabular}{cccccccc} 
Horizon & $\hat{\sigma}_{\text {VEC }}^{2}$ & $\hat{\sigma}_{\text {VEC }}^{2}$-adj. & $\hat{\sigma}_{R W}^{2}$ & $\hat{\sigma}_{\text {VEC }}^{2}$-adj. & $\hat{\sigma}_{\text {VAR }}^{2}$ & $\begin{array}{c}\hat{\sigma}_{\text {VEC }}^{2} / \hat{\sigma}_{R W}^{2} \\
(t \text {-value })\end{array}$ & $\begin{array}{c}\hat{\sigma}_{\text {VEC }}^{2} \hat{\sigma}_{\text {VAR }}^{2} \\
(t \text {-value })\end{array}$ \\
\hline \hline 1 & 0.553 & 0.291 & 0.474 & 0.404 & 0.489 & $1.17(1.19)$ & $1.13(0.98)$ \\
2 & 1.191 & 0.635 & 1.067 & 0.900 & 1.199 & $1.05(0.98)$ & $0.99(1.41)$ \\
3 & 1.471 & 0.889 & 1.719 & 1.155 & 1.951 & $0.86(1.11)$ & $0.86(2.14)$ \\
4 & 1.812 & 0.999 & 2.407 & 1.386 & 2.706 & $0.75(1.18)$ & $0.67(2.15)$ \\
5 & 2.012 & 1.006 & 2.970 & 1.500 & 3.243 & $0.68(1.33)$ & $0.62(2.20)$ \\
6 & 2.550 & 1.373 & 3.692 & 2.002 & 4.263 & $0.69(1.41)$ & $0.60(2.45)$ \\
7 & 2.915 & 1.585 & 4.114 & 2.321 & 4.946 & $0.71(1.49)$ & $0.59(2.64)$ \\
8 & 3.267 & 1.727 & 4.465 & 2.607 & 5.551 & $0.73(1.58)$ & $0.73(2.94)$ \\
9 & 3.673 & 2.044 & 4.963 & 2.952 & 6.218 & $0.74(1.73)$ & $0.59(3.21)$ \\
10 & 4.187 & 2.490 & 5.240 & 3.392 & 6.881 & $0.80(1.56)$ & $0.61(3.62)$ \\
11 & 5.333 & 3.462 & 5.772 & 4.456 & 8.149 & $0.92(1.25)$ & $0.65(4.07)$ \\
12 & 6.654 & 4.649 & 6.410 & 5.678 & 9.610 & $1.04(0.97)$ & $0.69(3.88)$ \\
\hline \hline
\end{tabular}

NOTE. Cases when the Clark-West test statistic is significant at the 10 percent level or better have been shaded. 
Table 2. Forecast evaluation: Real SEK/TCW alternative model

Panel A. Unrestricted model

\begin{tabular}{cccccccc} 
Horizon & $\hat{\sigma}_{V E C}^{2}$ & $\hat{\sigma}_{V E C}^{2}$-adj. & $\hat{\sigma}_{R W}^{2}$ & $\hat{\sigma}_{\text {VEC }}^{2}$-adj. & $\hat{\sigma}_{\text {VAR }}^{2}$ & $\begin{array}{c}\hat{\sigma}_{V E C}^{2} / \hat{\sigma}_{R W}^{2} \\
(t \text {-value })\end{array}$ & $\begin{array}{c}\hat{\sigma}_{V E C}^{2} / \hat{\sigma}_{\text {VAR }}^{2} \\
(t \text {-value })\end{array}$ \\
\hline \hline 1 & 0.532 & 0.468 & 0.474 & 0.521 & 0.485 & $1.12(0.12)$ & $1.10(-0.88)$ \\
2 & 1.172 & 1.113 & 1.067 & 1.166 & 1.109 & $1.10(-0.36)$ & $1.06(-1.35)$ \\
3 & 1.899 & 1.826 & 1.719 & 1.894 & 1.847 & $1.10(-0.69)$ & $1.03(-1.72)$ \\
4 & 2.522 & 2.440 & 2.407 & 2.517 & 2.489 & $1.05(-0.17)$ & $1.01(-0.95)$ \\
5 & 3.075 & 2.979 & 2.970 & 3.068 & 3.006 & $1.04(-0.03)$ & $1.02(-0.98)$ \\
6 & 3.851 & 3.741 & 3.692 & 3.841 & 3.742 & $1.04(-0.13)$ & $1.03(-0.84)$ \\
7 & 4.346 & 4.223 & 4.114 & 4.330 & 4.213 & $1.06(-0.24)$ & $1.03(-0.70)$ \\
8 & 4.620 & 4.479 & 4.465 & 4.599 & 4.482 & $1.03(-0.03)$ & $1.03(-0.50)$ \\
9 & 5.093 & 4.933 & 4.963 & 5.065 & 4.897 & $1.03(0.05)$ & $1.04(-0.62)$ \\
10 & 5.327 & 5.144 & 5.240 & 5.290 & 5.105 & $1.02(0.16)$ & $1.04(-0.64)$ \\
11 & 5.846 & 5.639 & 5.772 & 5.798 & 5.597 & $1.01(0.20)$ & $1.04(-0.62)$ \\
12 & 6.610 & 6.376 & 6.410 & 6.551 & 6.288 & $1.03(0.04)$ & $1.05(-0.64)$ \\
\hline \hline
\end{tabular}

\section{Panel B. Restricted model}

\begin{tabular}{cccccccc} 
Horizon & $\hat{\sigma}_{V E C}^{2}$ & $\hat{\sigma}_{V E C}^{2}$-adj. & $\hat{\sigma}_{R W}^{2}$ & $\hat{\sigma}_{V E C}^{2}$-adj. & $\hat{\sigma}_{V A R}^{2}$ & $\begin{array}{c}\hat{\sigma}_{V E C}^{2} / \hat{\sigma}_{R W}^{2} \\
(t \text {-value })\end{array}$ & $\begin{array}{c}\hat{\sigma}_{V E C}^{2} / \hat{\sigma}_{V A R}^{2} \\
(t \text {-value })\end{array}$ \\
\hline \hline 1 & 0.498 & 0.425 & 0.474 & 0.466 & 0.485 & $1.05(0.62)$ & $1.03(0.27)$ \\
2 & 1.163 & 1.082 & 1.067 & 1.119 & 1.109 & $1.09(-0.08)$ & $1.05(-0.07)$ \\
3 & 1.925 & 1.825 & 1.719 & 1.866 & 1.847 & $1.12(-0.43)$ & $1.04(-0.08)$ \\
4 & 2.617 & 2.500 & 2.407 & 2.539 & 2.489 & $1.09(-0.36)$ & $1.05(-0.17)$ \\
5 & 3.259 & 3.116 & 2.970 & 3.159 & 3.006 & $1.10(-0.56)$ & $1.08(-0.48)$ \\
6 & 4.120 & 3.948 & 3.692 & 3.994 & 3.742 & $1.12(-0.86)$ & $1.10(-0.70)$ \\
7 & 4.797 & 4.589 & 4.114 & 4.640 & 4.213 & $1.17(-1.34)$ & $1.14(-1.03)$ \\
8 & 5.319 & 5.069 & 4.465 & 5.124 & 4.482 & $1.19(-1.43)$ & $1.19(-1.31)$ \\
9 & 5.962 & 5.663 & 4.963 & 5.727 & 4.897 & $1.20(-1.22)$ & $1.22(-1.46)$ \\
10 & 6.272 & 5.924 & 5.240 & 5.996 & 5.105 & $1.20(-1.11)$ & $1.23(-1.40)$ \\
11 & 6.832 & 6.422 & 5.772 & 6.509 & 5.597 & $1.18(-0.99)$ & $1.22(-1.34)$ \\
12 & 7.638 & 7.166 & 6.410 & 7.268 & 6.288 & $1.19(-1.07)$ & $1.21(-1.46)$ \\
\hline \hline
\end{tabular}

Panel C. Restricted model with real interest rate differential

\begin{tabular}{cccccccc} 
Horizon & $\hat{\sigma}_{\text {VEC }}^{2}$ & $\hat{\sigma}_{\text {VEC }}^{2}$-adj. & $\hat{\sigma}_{R W}^{2}$ & $\hat{\sigma}_{\text {VEC }}^{2}$-adj. & $\hat{\sigma}_{\text {VAR }}^{2}$ & $\begin{array}{c}\hat{\sigma}_{\text {VEC }}^{2} / \hat{\sigma}_{R W}^{2} \\
(t \text {-value })\end{array}$ & $\begin{array}{c}\hat{\sigma}_{\text {VEC }}^{2}\left(\hat{\sigma}_{\text {VAR }}^{2}\right. \\
(t \text {-value })\end{array}$ \\
\hline \hline 1 & 0.417 & 0.307 & 0.474 & 0.372 & 0.451 & $0.88(2.25)$ & $0.92(1.22)$ \\
2 & 0.945 & 0.819 & 1.067 & 0.897 & 1.013 & $0.89(1.75)$ & $0.93(1.19)$ \\
3 & 1.481 & 1.323 & 1.719 & 1.432 & 1.659 & $0.86(1.82)$ & $0.89(1.59)$ \\
4 & 2.045 & 1.887 & 2.407 & 2.005 & 2.282 & $0.85(2.35)$ & $0.90(1.57)$ \\
5 & 2.516 & 2.341 & 2.970 & 2.484 & 2.778 & $0.85(2.23)$ & $0.91(1.69)$ \\
6 & 3.298 & 3.108 & 3.692 & 3.273 & 3.573 & $0.89(2.00)$ & $0.92(1.78)$ \\
7 & 3.854 & 3.644 & 4.114 & 3.836 & 4.046 & $0.94(1.42)$ & $0.95(1.45)$ \\
8 & 4.359 & 4.125 & 4.465 & 4.343 & 4.482 & $0.98(0.84)$ & $0.97(1.10)$ \\
9 & 4.962 & 4.707 & 4.963 & 4.945 & 4.998 & $1.00(0.49)$ & $0.99(0.45)$ \\
10 & 5.346 & 5.094 & 5.240 & 5.323 & 5.336 & $1.02(0.26)$ & $1.00(0.08)$ \\
11 & 5.984 & 5.691 & 5.772 & 5.952 & 5.892 & $1.04(0.15)$ & $1.02(-0.25)$ \\
12 & 7.011 & 6.667 & 6.410 & 6.962 & 6.839 & $1.09(-0.40)$ & $1.03(-0.33)$ \\
\hline \hline
\end{tabular}

NOTE. Cases when the Clark-West test statistic is significant at the 10 percent level or better have been shaded. 
Table 3 Forecast evaluation: Nominal SEK/TCW, restricted model with nominal interest rate differential

Panel A. Benchmark model

\begin{tabular}{|c|c|c|c|c|c|c|c|}
\hline Horizon & $\hat{\sigma}_{V E C}^{2}$ & $\hat{\sigma}_{V E C}^{2}$-adj. & $\hat{\sigma}_{R W}^{2}$ & $\hat{\sigma}_{V E C}^{2}$-adj. & $\hat{\sigma}_{V A R}^{2}$ & $\begin{array}{c}\hat{\sigma}_{V E C}^{2} / \hat{\sigma}_{R W}^{2} \\
(t \text {-value })\end{array}$ & $\begin{array}{c}\hat{\sigma}_{V E C}^{2} / \hat{\sigma}_{V A R}^{2} \\
\text { (t-value) }\end{array}$ \\
\hline 1 & 0.522 & 0.323 & 0.425 & 0.466 & 0.454 & $1.23(0.95)$ & $1.15(-0.19)$ \\
\hline 2 & 1.194 & 0.834 & 0.984 & 1.111 & 1.164 & $1.21(0.52)$ & $1.03(0.44)$ \\
\hline 3 & 1.659 & 1.248 & 1.568 & 1.601 & 1.827 & $1.06(0.78)$ & $0.91(1.77)$ \\
\hline 4 & 2.290 & 1.667 & 2.220 & 2.238 & 2.420 & $1.37(0.88)$ & $0.95(1.26)$ \\
\hline 5 & 3.133 & 2.237 & 2.755 & 3.085 & 2.989 & $1.14(0.64)$ & $1.05(-0.53)$ \\
\hline 6 & 4.429 & 3.093 & 3.394 & 4.348 & 3.804 & $1.30(0.27)$ & $1.16(-1.41)$ \\
\hline 7 & 5.696 & 3.732 & 3.750 & 5.523 & 4.389 & $1.52(0.01)$ & $1.30(-1.43)$ \\
\hline 8 & 6.958 & 4.112 & 4.069 & 6.607 & 4.742 & $1.71(-0.02)$ & $1.47(-1.37)$ \\
\hline 9 & 9.024 & 5.019 & 4.450 & 8.381 & 5.452 & $2.03(-0.18)$ & $1.66(-1.35)$ \\
\hline 10 & 11.516 & 5.912 & 4.704 & 10.404 & 6.281 & $2.45(-0.31)$ & $1.83(-1.34)$ \\
\hline 11 & 15.052 & 7.225 & 5.052 & 13.230 & 7.603 & $2.98(-0.48)$ & $1.98(-1.32)$ \\
\hline 12 & 20.274 & 9.716 & 5.568 & 17.376 & 9.388 & $3.64(-0.75)$ & $2.16(-1.34)$ \\
\hline
\end{tabular}

Panel B. Alternative model

\begin{tabular}{cccccccc} 
Horizon & $\hat{\sigma}_{\text {VEC }}^{2}$ & $\hat{\sigma}_{\text {VEC }}^{2}$-adj. & $\hat{\sigma}_{R W}^{2}$ & $\hat{\sigma}_{\text {VEC }}^{2}$-adj. & $\hat{\sigma}_{\text {VAR }}^{2}$ & $\begin{array}{c}\hat{\sigma}_{\text {VEC }}^{2}\left(\hat{\sigma}_{R W}^{2}\right. \\
(t \text {-value })\end{array}$ & $\begin{array}{c}\hat{\sigma}_{\text {VEC }}^{2} \hat{\sigma}_{\text {VAR }}^{2} \\
(t \text {-value })\end{array}$ \\
\hline \hline 1 & 0.406 & 0.328 & 0.425 & 0.370 & 0.409 & $0.96(1.46)$ & $0.99(0.70)$ \\
2 & 0.932 & 0.787 & 0.984 & 0.865 & 0.936 & $0.95(1.17)$ & $1.00(0.60)$ \\
3 & 1.397 & 1.171 & 1.568 & 1.294 & 1.454 & $0.89(1.52)$ & $0.96(0.81)$ \\
4 & 1.815 & 1.559 & 2.220 & 1.699 & 1.942 & $0.82(2.14)$ & $0.93(0.89)$ \\
5 & 2.172 & 1.874 & 2.755 & 2.041 & 2.334 & $0.79(2.27)$ & $0.93(0.93)$ \\
6 & 2.679 & 2.354 & 3.394 & 2.544 & 2.870 & $0.79(2.23)$ & $0.93(0.88)$ \\
7 & 3.055 & 2.666 & 3.750 & 2.911 & 3.147 & $0.81(2.04)$ & $0.81(0.56)$ \\
8 & 3.342 & 2.892 & 4.069 & 3.188 & 3.335 & $0.82(1.85)$ & $1.00(0.30)$ \\
9 & 3.819 & 3.319 & 4.450 & 3.655 & 3.717 & $0.86(1.52)$ & $1.03(0.12)$ \\
10 & 4.105 & 3.608 & 4.704 & 3.931 & 3.955 & $0.87(1.36)$ & $1.04(0.04)$ \\
11 & 4.457 & 3.970 & 5.052 & 4.269 & 4.352 & $0.88(1.41)$ & $1.02(0.13)$ \\
12 & 5.057 & 4.604 & 5.568 & 4.853 & 5.105 & $0.91(1.32)$ & $0.99(0.40)$ \\
\hline \hline
\end{tabular}

NOTE. Cases when the Clark-West test statistic is significant at the 10 percent level or better have been shaded 


\section{Earlier Working Papers:}

For a complete list of Working Papers published by Sveriges Riksbank, see www.riksbank.se

Evaluating Implied RNDs by some New Confidence Interval Estimation Techniques

by Magnus Andersson and Magnus Lomakka....

Taylor Rules and the Predictability of Interest Rates

by Paul Söderlind, Ulf Söderström and Anders Vredin ......................................................... 2003:147

Inflation, Markups and Monetary Policy

by Magnus Jonsson and Stefan Palmqvist.....

Financial Cycles and Bankruptcies in the Nordic Countries by Jan Hansen........................................ 2003:149

Bayes Estimators of the Cointegration Space by Mattias Villani .................................................. 2003:150

Business Survey Data: Do They Help in Forecasting the Macro Economy?

by Jesper Hansson, Per Jansson and Mårten Löf

The Equilibrium Rate of Unemployment and the Real Exchange Rate:

An Unobserved Components System Approach by Hans Lindblad and Peter Sellin ........................ 2003:152

Monetary Policy Shocks and Business Cycle Fluctuations in a

Small Open Economy: Sweden 1986-2002 by Jesper Lindé

Bank Lending Policy, Credit Scoring and the Survival of Loans by Kasper Roszbach .......................... 2003:154

Internal Ratings Systems, Implied Credit Risk and the Consistency of Banks' Risk

Classification Policies by Tor Jacobson, Jesper Lindé and Kasper Roszbach .................................. 2003:155

Monetary Policy Analysis in a Small Open Economy using Bayesian Cointegrated

Structural VARs by Mattias Villani and Anders Warne

Indicator Accuracy and Monetary Policy: Is Ignorance Bliss? by Kristoffer P. Nimark ........................ 2003:157

Intersectoral Wage Linkages in Sweden by Kent Friberg .......................................................... 2003:158

Do Higher Wages Cause Inflation? by Magnus Jonsson and Stefan Palmqvist ............................. 2004:159

Why Are Long Rates Sensitive to Monetary Policy by Tore Ellingsen and Ulf Söderström .................. 2004:160

The Effects of Permanent Technology Shocks on Labor Productivity

and Hours in the RBC model by Jesper Lindé........................................................................ 2004:161

Credit Risk versus Capital Requirements under Basel II: Are SME Loans and Retail

Credit Really Different? by Tor Jacobson, Jesper Lindé and Kasper Roszbach

Exchange Rate Puzzles: A Tale of Switching Attractors

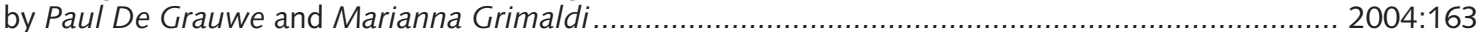

Bubbles and Crashes in a Behavioural Finance Model

by Paul De Grauwe and Marianna Grimaldi.

Multiple-Bank Lending: Diversification and Free-Riding in Monitoring

by Elena Carletti, Vittoria Cerasi and Sonja Daltung.............................................................. 2004:165

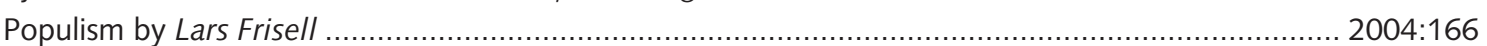

Monetary Policy in an Estimated Open-Economy Model with Imperfect Pass-Through

by Jesper Lindé, Marianne Nessén and Ulf Söderström

Is Firm Interdependence within Industries Important for Portfolio Credit Risk?

by Kenneth Carling, Lars Rönnegård and Kasper Roszbach

$2004: 168$

How Useful are Simple Rules for Monetary Policy? The Swedish Experience

by Claes Berg, Per Jansson and Anders Vredin

The Welfare Cost of Imperfect Competition and Distortionary Taxation

by Magnus Jonsson

A Bayesian Approach to Modelling Graphical Vector Autoregressions

by Jukka Corander and Mattias Villani

Do Prices Reflect Costs? A study of the price- and cost structure of retail payment

services in the Swedish banking sector 2002 by Gabriela Guibourg and Biörn Segendorf

Excess Sensitivity and Volatility of Long Interest Rates: The Role of Limited

Information in Bond Markets by Meredith Beechey.

State Dependent Pricing and Exchange Rate Pass-Through

by Martin Flodén and Fredrik Wilander.

The Multivariate Split Normal Distribution and Asymmetric Principal

Components Analysis by Mattias Villani and Rolf Larsson

Firm-Specific Capital, Nominal Rigidities and the Business Cycle

by David Altig, Lawrence Christiano, Martin Eichenbaum and Jesper Lindé

Estimation of an Adaptive Stock Market Model with Heterogeneous Agents by Henrik Amilon ........ 2005:177

Some Further Evidence on Interest-Rate Smoothing: The Role of Measurement

Errors in the Output Gap by Mikael Apel and Per Jansson...... 
Swedish Intervention and the Krona Float, 1993-2002

by Owen F. Humpage and Javiera Ragnartz

A Simultaneous Model of the Swedish Krona, the US Dollar and the Euro

by Hans Lindblad and Peter Sellin....

Testing Theories of Job Creation: Does Supply Create Its Own Demand?

by Mikael Carlsson, Stefan Eriksson and Nils Gottfries.

Down or Out: Assessing The Welfare Costs of Household Investment Mistakes

by Laurent E. Calvet, John Y. Campbell and Paolo Sodini

Efficient Bayesian Inference for Multiple Change-Point and Mixture Innovation Models

by Paolo Giordani and Robert Kohn

Derivation and Estimation of a New Keynesian Phillips Curve in a Small Open Economy

by Karolina Holmberg....

Technology Shocks and the Labour-Input Response: Evidence from Firm-Level Data

by Mikael Carlsson and Jon Smedsaas

Monetary Policy and Staggered Wage Bargaining when Prices are Sticky

by Mikael Carlsson and Andreas Westermark

The Swedish External Position and the Krona by Philip R. Lane....

Price Setting Transactions and the Role of Denominating Currency in FX Markets

by Richard Friberg and Fredrik Wilander....

The geography of asset holdings: Evidence from Sweden

by Nicolas Coeurdacier and Philippe Martin

Evaluating An Estimated New Keynesian Small Open Economy Model

by Malin Adolfson, Stefan Laséen, Jesper Lindé and Mattias Villani ....

The Use of Cash and the Size of the Shadow Economy in Sweden

by Gabriela Guibourg and Björn Segendorf.

Bank supervision Russian style: Evidence of conflicts between micro- and macro-

prudential concerns by Sophie Claeys and Koen Schoors

Optimal Monetary Policy under Downward Nominal Wage Rigidity

by Mikael Carlsson and Andreas Westermark.

Financial Structure, Managerial Compensation and Monitoring

by Vittoria Cerasi and Sonja Daltung

Financial Frictions, Investment and Tobin's q by Guido Lorenzoni and Karl Walentin

Sticky Information vs. Sticky Prices: A Horse Race in a DSGE Framework

by Mathias Trabandt.

Acquisition versus greenfield: The impact of the mode of foreign bank entry

on information and bank lending rates by Sophie Claeys and Christa Hainz

Nonparametric Regression Density Estimation Using Smoothly Varying Normal Mixtures

by Mattias Villani, Robert Kohn and Paolo Giordani ....

The Costs of Paying - Private and Social Costs of Cash and Card

by Mats Bergman, Gabriella Guibourg and Biörn Segendorf.... 
Sveriges Riksbank

Visiting address: Brunkebergs torg 11

Mail address: se-103 37 Stockholm

Website: www.riksbank.se

Telephone: +46878700 00, Fax: +468210531

E-mail: registratorn@riksbank.se 